\title{
ESSENTIAL NORM OF THE WEIGHTED DIFFERENTIATION COMPOSITION OPERATOR BETWEEN BLOCH-TYPE SPACES
}

\author{
CUi Chen AND Yu-Xia Liang
}

Abstract. We give some characterizations for the boundedness and compactness of weighted differentiation composition operator $D_{\varphi, u}^{m}$ between different Bloch spaces, and also estimate the essential norms of the operator, complementing some recent results in the literature.

Mathematics subject classification (2010): 47B38, 30H30, 30H05, 47B33.

Keywords and phrases: Weighted differentiation composition operator, essential norm, Bloch-type space, boundedness, compactness.

\section{REFERENCES}

[1] C. C. Cowen and B. D. MacCluer, Composition Operators on Spaces of Analytic Functions, CRC Press, Boca Raton, FL, 1995.

[2] Z. S. FANG AND Z. H. ZHOU, Essential norms of composition operators between Bloch type spaces in the polydisk, Arch. Math., 99, (2012), 547-556.

[3] Z. S. FANG AND Z. H. ZHOU, New characterizations of the weighted composition operators between Bloch type spaces in the polydisk, Canad. Math. Bull., 57, 4 (2014), 794-802.

[4] O. Hyvärinen, M. Kemappainen, M. Lindström, A. Rautio And E. SaukKo, The essential norms of weighted composition operators on weighted Banach spaces of analytic function, Integr. Equ. Oper. Theory, 72, (2012), 151-157.

[5] O. HYVÄRINEN AND M. LINDSTRÖM, Estimates of essential norms of weighted composition operators between Bloch-type spaces, J. Math. Anal. Appl., 393, (2012), 38-44.

[6] S. Li AND S. STEVIĆ, Composition followed by differentiation between Bloch type spaces, J. Comput. Anal. Appl., 9, 2 (2007), 195-205.

[7] S. Li AND S. STEviĆ, Composition followed by differentiation from mixed-norm spaces to $\alpha$-Bloch spaces, Sb. Math., 199, 12 (2008), 1847-1857.

[8] S. Li And S. Stević, Composition followed by differentiation between $H^{\infty}$ and $\alpha$-Bloch spaces, Houston J. Math., 35, 1 (2009), 327-340.

[9] S. Li AND S. STEVIĆ, Weighted differentiation composition operators from the logarithmic Bloch space to the weighted-type space, An. Stiint. Univ. "Ovidius" Constanta Ser. Mat., 24, 3 (2016), 223 240.

[10] Y. X. LiAng AND Z. H. ZHOU, Essential norms of the product of differentiation and composition operators between Bloch-type spaces, Arch. Math., 100, 4, (2013), 347-360.

[11] Y. X. LIANG AND Z. H. ZHOU, New estimate of essential norm of composition followed by differentiation between Bloch-type spces, Banach J. Math. Anal., 8, (2014), 118-137.

[12] Y. LIU AND Y. YU, Weighted differentiation composition operators from mixed-norm to Zygmund spaces, Numer. Func. Anal. Opt., 31, 8 (2010), 936-954.

[13] B. D. MACCLUER AND R. ZHAO, Essential norms of weighted composition operators between Blochtype spaces, Rocky Mountain J. Math., 33, (2003),1437-1458.

[14] J. S. MANHAS AND R. ZHAO, New estimates of essential norms of weighted composition operators between Bloch type spaces, J. Math. Anal. Appl., 389, (2012), 32-47.

[15] S. STEvić, Essential norms of weighted composition operators from the $\alpha$-Bloch space to a weighted-type space on the unit ball, Abstr. Appl. Anal., 2008, (2008), Article ID 279691. 
[16] S. STEVIĆ, Norm and essential norm of composition followed by differentiation from $\alpha$-Bloch spaces to $H_{\mu}^{\infty}$, Appl. Math. Comput., 207, (2009), 225-229.

[17] S. STEviĆ, On a new integral-type operator from the Bloch space to Bloch-type spaces on the unit ball, J. Math. Anal. Appl., 354, (2009), 426-434.

[18] S. Stević, Products of composition and differentiation operators on the weighted Bergman space, Bull. Belg. Math. Soc. Simon Stevin, 16, (2009), 623-635.

[19] S. STEVIĆ, Weighted differentiation composition operators from mixed-norm spaces to weighted-type spaces, Appl. Math. Comput., 211, (2009), 222-233.

[20] S. STEviĆ, Composition followed by differentiation from $H^{\infty}$ and the Bloch space to $n$th weightedtype spaces on the unit disk, Appl. Math. Comput., 216, (2010), 3450-3458.

[21] S. STEvić, Weighted differentiation composition operators from $H^{\infty}$ and Bloch spaces to $n$th weighted-type spaces on the unit disk, Appl. Math. Comput., 216, 12 (2010), 3634-3641.

[22] S. STEVIĆ, Weighted differentiation composition operators from the mixed-norm space to the nth weighted-type space on the unit disk, Abstr. Appl. Anal., 15, (2010), Article ID 246287.

[23] S. STEVIĆ, Weighted iterated radial composition operators between some spaces of holomorphic functions on the unit ball, Abstr. Appl. Anal., 2010, (2010), Article ID 801264.

[24] S. STEVIĆ, Characterizations of composition followed by differentiation between Bloch-type spaces, Appl. Math. Comput., 218, (2011), 4312-4316.

[25] S. STEVIĆ, Weighted radial operator from the mixed-norm space to the nth weighted-type space on the unit ball, Appl. Math. Comput., 218, (2012) 9241-9247.

[26] S. Stević, A.K. Sharma AND A. Bhat, Essential norm of products of multiplication composition and differentiation operators on weighted Bergman spaces, Appl. Math. Comput., 218, (2011), 23862397.

[27] S. Stević, A. K. Sharma And A. Bhat, Products of multiplication composition and differentiation operators on weighted Bergman spaces, Appl. Math. Comput., 217, (2011), 8115-8125.

[28] Y. Wu AND H. Wulan, Products of differentiation and composition operators on the Bloch Space, Collect. Math., 63, (2012), 93-107.

[29] H. Wulan, D. Zheng And K. Zhu, Compact composition operators on BMOA and the Bloch space, Proc. Amer. Math. Soc., 137, (2009), 3861-3868.

[30] Y. YU AND Y. LiU, The essential norm of a generalized composition operator between Bloch-type spaces and $Q_{K}$ type spaces, Complex Anal. Oper. Th., 6, (2012) 1231-1240.

[31] H. G. ZENG AND Z. H. ZHOU, Essential norm estimate of a composition operator between Bloch-type spaces in the unit ball, Rocky Mountain J. Math., 42, 3 (2012), 1049-1071.

[32] R. ZhaO, Essential norms of composition operators between Bloch type spaces, Proc. Amer. Math. Soc., 138, (2010), 2537-2546.

[33] Z. H. ZHOU, J. H. SHI, Compactness of composition operators on the Bloch space in classical bounded symmetric domains, Michigan Math. J., 50, (2002), 381-405.

[34] X. L. ZHU, Generalized weighted composition operators on Bloch-type spaces, J. Inequal. Appl., 2015, 59 (2015), 1-9.

[35] X. L. ZHU, Essential norm of generalized weighted composition operators on Bloch-type spaces, Appl. Math. Comput., 274, 1 (2016), 133-142. 